This item was submitted to Loughborough's Research Repository by the author.

Items in Figshare are protected by copyright, with all rights reserved, unless otherwise indicated.

\title{
Considering human factors and developing systems-thinking behaviours to ensure patient safety
}

\section{PLEASE CITE THE PUBLISHED VERSION}

https://doi.org/10.1211/CP.2018.20204352

\section{PUBLISHER}

Published by the Royal Pharmaceutical Society

\section{VERSION}

AM (Accepted Manuscript)

\section{PUBLISHER STATEMENT}

This work is made available according to the conditions of the Creative Commons Attribution-NonCommercialNoDerivatives 4.0 International (CC BY-NC-ND 4.0) licence. Full details of this licence are available at: https://creativecommons.org/licenses/by-nc-nd/4.0/

\section{LICENCE}

CC BY-NC-ND 4.0

\section{REPOSITORY RECORD}

Vopser, Helen, Rosemary Lim, Colin Knight, Paul Bowie, Brian Edwards, and Sue Hignett. 2019. "Considering Human Factors and Developing Systems-thinking Behaviours to Ensure Patient Safety". figshare. https://hdl.handle.net/2134/28474. 


\section{Considering Human Factors and developingSystems- thinking behaviours to ensure patient safety}

Helen Vosper, Rosemary Lim, Colin Knight, Paul Bowie, Brian Edwards, Sue Hignett , on behalf of the CIEHF Pharmaceutical Human Factors Special Interest Group

Medication errors are too frequently assigned as blame towards a single person. By considering these errors as a system-level failure, healthcare providers can take significant steps towards improving patient safety. The patient safety agenda has gathered pace since the US Institute of Medicine launched its 1990 report 'To err is human: building a safer health system, ${ }^{[1]}$. Analysis of landmark events including the UK's 'Mid-Staffs' crisis ${ }^{[2]}$ has also revealed that adverse events are rooted in system failures. A distinct patient safety research and educational agenda has emerged ${ }^{[2]}$.

'Systems thinking' is a way of better understanding complex workplace issues; exploring relationships between system elements to inform efforts to improve; and realising that 'cause and effect' are not necessarily closely related in space or time. This approach does not come naturally and is neither well-defined nor routinely practised in healthcare. When under stress, the human psyche often reduces complex reality to linear cause-and-effect chains. The need to identify a single cause of an incident is embedded in healthcare: patients and families understandably often need to see 'someone' held to account, and healthcare 'wrongs' fall under a tort system where assigning 'blame' releases compensation. We believe that real safety improvements require healthcare staff, leaders and decision-makers at all levels to develop systems-thinking competencies and behaviours

\section{Harm and safety}

Harm and safety are the results of complex systems, not single acts. Despite this, the terms 'safety' and 'systems' are frequently used in healthcare, yet they are rarely defined and are often used arbitrarily and interchangeably.

Dul et al. define a 'system' as “a set of interrelated (coupled) entities united in a joint purpose"[3] 'Entities' can be physical objects, technology, processes and relationships, as well as organisational and legal constraints. When entities are tightly coupled (explicitly linked and interdependent), specific changes can cascade rapidly through the system, which cause a ripple effect that may only be felt at a distance. While system size can, and does, vary, healthcare systems are often large, complex and sociotechnical. With so many interactions between entities, outcomes can be difficult to predict; a concept known as emergence. Because safety is an emergent property, safety management is highly complex. Unfortunately, emergent properties are often managed independently, rather than systematically.

We define safety, in relation to systems, as the level of system performance required to keep the incidence of harm (and risk) as low as reasonably practicable. While this definition requires consensus on 'acceptably low' incidence, it is more useful than the definitions used in healthcare, on the rare occasions when it has been defined. In these instances, safety is usually held as the prevention of 'medical error': something that is unachievable in a complex sociotechnical system. 'Medical error' unfairly blames individuals: adverse outcomes are inevitably issues related to systems, with multiple interacting contributory 
factors that vary over time and circumstances; this makes 'root causes' difficult to pin down.

\section{Problems for pharmacy}

Health and social care are being increasingly delivered in the community by multiprofessional teams that require "knowledge, skills and attributes to work across sectors"[4]. While some professions (particularly medicine and nursing) are more accustomed to this, pharmacy's recent integration has not been seamless $\frac{[5]}{\text {. }}$

There is a lack of understanding of the rapidly evolving pharmacist role, which is likely to see more involvement in managing illness through a pharmaceutical care model ${ }^{[6],[7]}$. This may mean taking sole responsibility (and accountability) for patient outcomes. There are obstacles to this transition; pharmacy's capacity for change is hampered by established interprofessional dynamics. Jorgenson et al. suggest that pharmacists interpret their roles through the lens of their relationship with doctors ${ }^{[5]}$. With uncertainty over relationships between accountability, responsibility and autonomy, we suggest that a lack of clarity of system design further inhibits change.

Education is key to developing safety competence. The Francis report recommended that clinical placement should be quality assured, because attitudes, values and behaviours of staff can influence student learning and undermine patient safety [2],[8]. Pharmacy is particularly affected: with the dearth of MPharm programme placements, bias attitudes stem from students' own pharmacy-related employment, invisible to academic staff; their influence on learning is, therefore, impossible to predict.

The legislative framework that allows dispensing errors to be treated as a criminal offence is also an issue for pharmacists. While successful prosecutions under the Medicines Act 1968 are rare, recent cases indicate prosecutors are willing to seek custodial sentences $\underline{[9]}$. Holding individuals responsible for errors contradicts fundamental safety science principles, is counter- productive to learning and inhibits the open reporting essential for understanding system behaviour. However, new legislation to protect pharmacists from prosecution was passed by committees in both the House of Lords and the House of Commons in December 2017.

\section{Human Factors as a framework for supporting safety}

Understanding safety as an emergent property is complicated by the difference between 'work as imagined' (defined within standard operating procedures [SOPs]) and what actually happens in a dynamic, pressurised workplace $\frac{[10]}{}$. The relationship between these two states must be explored during normal system operation, rather than with a focus on (comparatively rare) adverse events. The perceived value of the latter relies on flawed assumptions that there is an identifiable cause, and that this cause likely involves human error.

It is important to define the operating space within which performance can safely occur. In this way, errors can be contained to mitigate process deviation ('workarounds'). Incident investigations often identify errors, or deviations from or violations of SOPs, which are assumed to be the 'cause'; an approach often referred to as 'Safety-I' $[10]$. This approach fails to recognise that most workarounds occur safely as a result of necessary adaptive 
behaviour to 'get the job done'; i.e. humans responding to an inappropriate process design in a busy working environment, often with limited resources. Clamping down on all 'unsafe' deviations leads to 'terror of deviation,' which hinders continuous improvement.

'Safety-II' identifies key features of successful tasks; it reveals that errors, deviations and violations are all part of normal work, and are often necessary for delivering successful outcomes in poorly designed systems. These necessary adaptations are known as 'functional resonance', and identify weak points in the system and support intelligent redesign.

\section{How intelligent redesign may prevent wrong-route drug administration}

Wayne Jowett died following intrathecal injection of the chemotherapy vincristine, intended for intravenous delivery ${ }^{[11]}$. Cases like Jowett's have been rare worldwide, but in each, the use of luer connectors was a contributory factor. Their reliable leak-free connection of fluid and drug administration devices means they are routinely used regardless of route of administration, and have been linked with multiple wrong-route administration accidents. Future events could be prevented by redesigning processes and equipment so that drugs are intrathecally administered using only devices that cannot connect to intravenous equipment - a recommendation made by the National Patient Safety Agency in 200912].

\section{Human Factors and Ergonomics}

Human factors and ergonomics (HFE) practice has much to offer. In the UK, this is regulated by the Chartered Institute of Ergonomics and Human Factors (CIEHF). Like the General Pharmaceutical Council (GPhC), the CIEHF accredits education and training, and many HFE specialists are qualified to postgraduate level and beyond. HFE offers validated tools for modelling, redesigning and testing systems. Understanding HFE helps people to perform optimally and safely in complex systems, and all healthcare staff should develop basic HFE competencies to support their work.

The potential for this is beginning to be realised. The 2016 Care Quality Commission briefing recognised that applying HFE principles can reduce the risk of adverse events reoccurring, and Health Education England has invested in staff training with HFE taster workshops 13$],[14]$. Similarly, NHS Education for Scotland (NES) routinely delivers HFE workshops. Other HFE- related developments include national implementation of 'enhanced significant event analysis', a systems-based approach to team-learning from safety incidents ${ }^{[15]}$ and a human-factors critique of the existing general practice training curriculum ${ }^{[16]}$. Professional guidance for clinical educators on embedding HFE principles in healthcare curricula has also been published ${ }^{[17]}$. NES, along with the Royal College of Surgeons of Edinburgh (and multiple stakeholders), is leading the participatory design of a strategic plan to inform HFE integration, research and development, and building-related capacity and capability in NHS Scotland. 


\section{Mistaking Quality Improvement for HFE}

Are we not already considering HFE? In healthcare, HFE is sometimes confused with quality improvement (QI), which is an important mechanism for improving patient safety. While QI focuses on process and technical issues, HFE focuses on jointly optimising

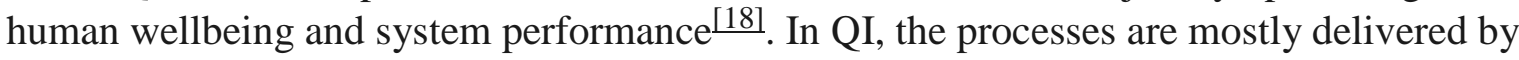
people; however, people are not the focus of the improvement. QI is an excellent tool for technically exploring processes, but without a holistic systems approach, effectiveness may be limited. We believe QI and HFE offer synergies; both need the other for successful system improvement.

Healthcare-specific conflation of the terms 'human factors' and 'factors of the human' also hampers effective embedding of healthcare HFE. The latter includes communication and team working, often called 'non-technical skills'. While non-technical skills training has proved effective in certain settings (surgical teams, for example), the lack of a wider design-based systems approach makes it unsuitable for systemic quality management. Even where genuine HFE approaches have been used in healthcare, the benefits are not always fully realised because HFE input occurred too late: after the initial design phase.

\section{The future}

Evidence from other sectors suggests that HFE can improve patient safety, but there is much to do. In the case of Jowett (See 'Box: Intelligent redesign may prevent wrong-route drug administration'), despite the National Patient Safety Agency’s recommendations, compliance for all similar scenarios has not yet been achieved worldwide. Such a change requires multisector co-operation, including manufacturing and regulatory bodies, as well as healthcare organisations. Reducing the risk of wrong-route administration does not introduce new risks.

Taking HFE approaches can address problems such as this. Developing HFE competencies has implications for education and the aforementioned guidance can help support the embedding of HFE into curricula ${ }^{[19]}$. HFE can be supported in pharmacy by engaging with the CIEHF Pharmaceutical Human Factors Special Interest Group. This UK forum allows pharmaceutical professionals to explore HFE's impact on safety, wellbeing, quality and productivity in the healthcare product system, from factory to bedside, in a way that it has not been explored before.

\section{References}

[1] Kohn LT, Corrigan JM \& Donaldson MS. To Err Is Human — Building A Safer Health System. 2000. Washington, DC: National Academy Press

[2] Francis R. The Mid Staffordshire NHS Foundation Trust Public Enquiry. 2013. Available at: http://www.midstaffspublicinquiry.com/report (accessed February 2018)

[3] Dul J, Bruder R, Buckle P et al. A strategy for human factors/ergonomics: developing the discipline and profession. Ergonomics 2012;55(4):377-395. doi: 10.1080/00140139.2012.661087

[4] Gosling S. Changing imperatives in workforce planning: implications for health and social care education. Int J Pract based Learn Health Soc Care 2013;1(2):64-74. doi: 10.11120/pblh.2013.00018

[5] Jorgenson D, Laubscher T, Lyons D et al. Integrating pharmacists into primary care teams: barriers and facilitators. Int J Pharm Pract 2014;22(4):292-299. doi: 10.1111/ijpp.12080

[6] Rosenthal M, Zubin A \& Tsuyuki RT. Are pharmacists the ultimate barrier to pharmacy practice 
change? Can Pharm J 2010; 143(1):37-42. doi: 10.3821/1913-701X-143.1.37

[7] The Scottish Government. Prescription for excellence: a vision and action plan for the right pharmaceutical care through integrated partnerships and innovation. 2013. Available at:

http://www.gov.scot/resource/0043/00434053.pdf (accessed February 2018)

[8] Vosper H \& Hignett S. Factors influencing the development of effective error management competencies in undergraduate UK pharmacy students. Available at: https://dspace.lboro.ac.uk/dspace-

jspui/bitstream/2134/23829/6/Hignett_068Vosper.pdf (accessed February 2018)

[9] Langley C. Pharmacy legislation: public protector or professional hindrance? Med Law Rev

2013;22(1):87-108. doi: 10.1093/medlaw/fwt037

[10]Hollnagel E. From Safety-I to Safety-II: a white paper. Available at:

https://www.england.nhs.uk/signuptosafety/wp-content/uploads/sites/16/2015/10/safety-1- safety-2-whte-

papr.pdf (accessed February 2018)

[11]Balen P. Gross negligence manslaughter: Wayne Jowett (deceased). AvMA Med Leg J

2004;10(1):25-27. doi: 10.1258/135626204322756574

[12]Cook TM. Non-Luer connectors: are we nearly there yet? Anaesthesia 2012;67:784-792. doi: 10.1111/j.1365-2044.2012.07154.X

[13] Care Quality Commission. Briefing: learning from serious incidents in NHS acute hospitals. A review of the quality of investigation reports. Available at:http://www.cqc.org.uk/content/briefinglearning-serious-incidents-nhs-acute-hospitals (accessed February 2018)

[14] Hignett S, Lang A, Pickup L et al. More holes than cheese. What prevents the delivery of effective, high quality, and safe healthcare in England? Ergonomics 61(1):5-14. doi: 10.1080/00140139.2016.1245446

[15] Bowie P, McNaughton E, Bruce D et al. Enhancing: exploring personal impact and applying systems thinking in primary care the effectiveness of significant event analysis: exploring personal impact and applying systems thinking in primary care. J Contin Educ Health Prof 2016;36(3):195-205. doi: 10.1097/CEH.0000000000000098

[16] McKay J, Pickup L, Atkinson S et al. Human factors in general practice - early thoughts on the educational focus for specialty training and beyond. Educ Prim Care 2016;27(3):162- 171. doi: $\underline{10.1080 / 14739879.2016 .1181533}$

[17] Vosper H, Bowie P \& Hignett S. Twelve tips for embedding human factors and ergonomics principles in healthcare educational curricula and programmes. Med Teach 2017. doi: 10.1080/0142159X.2017.1387240

[18] Hignett S, Jones EL, Miller D et al. Human factors and ergonomics and quality improvement science: integrating approaches for safety in healthcare. BMJ Qual Saf 2015;24:250-254. doi: $\underline{10.1136 / \text { bmjqs-2014-003623 }}$

[19] Clinical Human Factors Group. Human factors in healthcare. A concordat from the National Quality Board. Available at: http://chfg.org/editorial/nqb-human-factors-concordat/ (accessed February 2018) 